\title{
Late-acting self-incompatibility and a narrow floral tube as selective forces for stylar dimorphism in Narcissus (Amaryllidaceae): A response to Simón- Porcar
}

\author{
Amy E. Faivre \\ Amy E. Faivre (aefaivre@cedarcrest.edu), Department of Biological Sciences, Cedar Crest College, Allentown, PA \\ 18104, United States
}

\begin{abstract}
Simón-Porcar proposes an alternative origin in the evolutionary pathway to heterostyly as described in a model proposed by Lloyd and Webb. Below I summarize her key points and namely consider the implications of comparing her model to ideas within the Charlesworth and Charlesworth model. The hypothesis that she has chosen to propose is similar to ones that others have proposed for this same genus, thus I have tried to distinguish how Simón-Porcar's hypothesis differs from theirs, as well as give credit to their contributions to these ideas. Finally, I have added a few more suggestions related to testing her hypothesis.
\end{abstract}

Keywords: distyly, heterostyly, ovule discounting, selfincompatibility, Narcissus, Boranginaceae

Simón-Porcar (2018) has carefully examined the Lloyd and Webb (1992) model for the evolution of heterostyly and suggested an alternative origin to their proposed pathway. She first explains the Lloyd and Webb (1992) model, inspired by Darwin's (1877) writings. She also discusses how others have explored this model in relation to the evolution of stigma dimorphisms and heterostyly in Narcissus (Barrett et al. 1996, Cesaro et al. 2004, Graham and Barrett 2004). The significant differences between her model and that of Lloyd and Webb (1992) are that Simón-Porcar proposes an alternative initial floral morphology, the potential for variable style lengths to be present until selection inevitably favors approximately two style heights, and the presence of a lateacting self-incompatibility system (LSI). Once these steps have evolved, her model converges to the pathway of the Lloyd and Webb (1992) model. This is clearly represented in her Figure 1, where she proposes that some taxa may have both wide, funnel-shaped corollas ("opentube flowers") and styles of variable heights throughout populations. These same taxa would also have a LSI. In flowers of this wide, funnel-shaped morphology, there is no selective pressure for a stylar dimorphism to evolve as self pollen would distribute equally on styles of any height. However, if some individuals evolve to have a narrower corolla, there would be a significant increase in self-interference. This coupled with the LSI leads to specific flowers with stigmas positioned at a similar height as the anther whorls in the narrowed corolla tube (namely, anthers in the lower whorl) to have reduced levels of fitness. Through disruptive selection (because she assumes style height is heritable), two morphs evolve - one with the stigma above the lower anther whorl (a flower morphology known as approach herkogamy) and one with the stigma below the lower anther whorls (a flower known as reverse herkogamy). As Simón-Porcar describes, her model differs in having a gradual process of disruptive selection, rather than a single mutation that generates the flower morphology needed to continue down the pathway predicted by Lloyd and Webb (1992) for the evolution of heterostyly. Her model also differs from Barrett et al. (1996), who envisions the narrowing 
of the corolla would ultimately be an important step towards the evolution of distyly because it would improve the precision of pollinators transferring pollen between floral morphs, specifically floral morphs of reciprocal herkogamy (where the anther heights of flowers of the long-style morph would align with the stigma heights of the short-style morph and vice-versa). Simón-Porcar discusses the importance of enhancement of cross-pollination between flowers of the different stylar morphs, but this is later in the model, following the selection of avoiding self-interference. Barrett et al. (1996) also proposed that ovule discounting would be an important selective force, similar to aspects of SimónPorcar's model, but on its own it would not be sufficient to select for the maintenance of two floral morphologies in a population. Their quantitative model focuses on a population with reverse and approach herkogamy, whereas Simón-Porcar envisions a population with a spectrum of short to long style heights.

One of Simón-Porcar's strongest arguments for disruptive selection being a likely mechanism in generating a species with flowers of two stigma heights, is the data shown in her Figure 2. These data are taken from Arroyo et al. (2002), and show style heights measured in plants throughout a population with almost no style heights present aligning with the lower whorl of anthers. She does address the issue of why in the results of Arroyo et al. (2002) there can be overlap in the stigma position matching the heights of the upper anther whorls. She notes that because of the width of the corolla where the upper anther whorl is located, the stigmas and anthers there are separated in horizontal space-reducing the chance for self-interference.

Simón-Porcar may also want to address the shift from a wide corolla to one with a narrow tube. There is not a direct explanation for why this shift in morphology would occur, though she does mention several studies (Graham and Barrett 2004, Santos-Gally et al. 2013) where the evolutionary history of this transition has been well-documented in Narcissus.

Simón-Porcar's model is dependent upon the presence of a late-acting self-incompatibility system at the start of the pathway (this is a condition found in her model system Narcissus, and some other potential taxa that she names at the end of her paper). If this were not in place, then stigmas positioned in alignment with anthers in a narrow corolla tube might actually be at an advantage of receiving more pollen then stigmas not touching the anthers in populations where pollinators are limited. Because her model requires the LSI to be in place at the start, it does resemble a key feature of the Charlesworth and Charlesworth (1979) model, where the incompatibility system is modeled to evolve before differences in floral morphology. Simón-Porcar does emphasize, though, that the driving selective force in her model is the avoidance of self-interference. She does note the importance of cross-pollination and its selective effects especially as the floral morphology would progress towards a dimorphic form (at a point after where her pathway joins that of the Lloyd and Webb model (1992), but she still emphasizes that this is not the main selective pressure. The focus of Charlesworth and Charlesworth (1979) is the evolution of a complete reciprocal selfincompatibility system before the differences in floral morphology occur, thus different from the LSI described by Simón-Porcar. However, it is worth noting that the Charlesworth and Charlesworth (1979) model does consider the effects of selfing, inbreeding depression, and explores the selective effects of both an incomplete and complete self-incompatibility system in the evolution of the heterostylous incompatibility system. Simón-Porcar may want to draw a few more ties back to this model as she explores starting a model with LSI in place. Then again, because her model system (Narcissus) does not have the heterostylous incompatibility system, perhaps a comparison to the Charlesworth and Charlesworth (1979) model is less relevant; LSI is a different incompatibility system than the heterostylous incompatibility system.

To test her hypothesis, Simón-Porcar has suggested three main approaches. Her first suggestion is to model the cost of male and female function with different stylar phenotypes over multiple generations. It is a little unclear how much is a suggestion to gather pollen load and seed set data in the field and how much would involve mathematical modeling. Some of the field data (and measurements), as she says, are available from SantosGally et al. (2013) and she herself provides some pollen load and seed set data from her work on Narcissus papyraceus (Simón-Porcar, unpublished). Barrett et al. (1996) clearly have done quite a bit of measuring of style and anther height variation, too, though pollen load is not as much of a focus of their research in the 1996 paper. Simón-Porcar's approach is not something that could be done easily, but could be a great dissertation project, given the appropriate model system (see her suggestions of possible taxonomic groups below). In terms of choice of taxa for testing her hypothesis, Simón-Porcar and Santos-Gally et al. (2013) both mention that Amaryllidaceae and Boraginaceae differ in their expression of heterostyly compared with other taxonomic groups. Simón-Porcar stresses the unique LSI that does not work like the standard heterostylous incompatibility system and Santos-Galley et al. (2013) emphasizes the frequent presence of taxa with stylar dimorphisms throughout these families, a morphology they both say is less frequently found in the other 28 angiosperm families with heterostylous members.

Simón-Porcar's second approach would be the use of phylogenies to map the progression of character transitions from having wide (vs. narrow) corolla tubes and the acquisition of LSI, followed by style dimorphism. Though this approach is also mammoth, if phylogenies 
are not available, arguably there are some published phylogenies that can be reanalyzed with this approach. Simón-Porcar names one of these that contains some of the data that she needs, the phylogeny done on the Narcissus genus by Graham and Barrett (2004). She critiques a portion of the taxa coding on their phylogeny, indicating that subsequent research suggests some of the taxa coded as monomorphic do in fact have stylar dimorphisms. Her focus is on the basal taxa of the Narcissus phylogeny (Graham and Barrett 2004), but I might suggest a study involving taxa in their clade corresponding to $N$. poeticus through $N$. triandrus, since it would appear this clade contains monomorphic and one heterostylous species (though being tristylous may complicate the test), and $N$. poeticus which is coded as having a narrow corolla, but does not have a stylar dimorphism. Another interesting section of the phylogeny is $N$. albimarginatus, the only Narcissus species said to have distyly, rather than stylar dimorphism (though lacking the heterostylous incompatibility system) (Arroyo and Barrett 2000). This species is part of a clade of other species with narrow corollas and stylar dimorphisms, an interesting set of taxa on which to test the latter part of the model, transitioning from stylar dimorphism to distyly. Other candidate taxa that Simón-Porcar recommends for study are from Boraginaceae. Specifically, I might recommend Amsinckia. In a phylogenetic study Schoen et al. (1997) explored outcrossing and selfing and the possibility of heterostyly evolving or being lost in this genus of Boranginaceae. They mention issues of cryptic self-incompatibility and variation in style heights. Likewise, earlier studies by Casper et al. (1988) shed some light on the cryptic incompatibility system of one species of Amsinckia. These are not quite the same as what Simón-Porcar proposes, but might be another area to examine, given that a phylogeny exists for these heterostylous and non-heterostylous taxa.

Simón-Porcar's third approach for testing her hypothesis involves trying to understand the genetic mechanism driving the stylar dimorphism in Narcissus. This, like her first approach seems like an extensive project. She mentions ontogenetic studies that have been done to understand the development of stylar dimorphisms (Faivre 2000). She might also look at the techniques of Cohen et al. (2009) who examined differences at the cellular level in styles of a heterostylous species and closely related homostylous (all styles at the same height) species. However, understanding the underlying genetics will take a whole different set of tools, as SimónPorcar acknowledges (e.g. genomic and transcriptomic techniques), such as the preliminary explorations of the Primula genome (Nowak et al. 2015).

In conclusion, I think Simón-Porcar has proposed an interesting alteration to the Lloyd and Webb (1992) model. In a number of studies on Narcissus by Spencer
Barrett and coauthors they propose (Barrett et al. 1996, Barrett et al. 2000, Arroyo et al. 2002, Cesaro et al. 2004, Graham and Barrett, 2004, to name a few) the importance of the narrow corolla tube to the evolution of heterostyly. However, Simón-Porcar has done a nice job of codifying it in this paper, as well as putting the main focus on the avoidance of selfing, rather than the promotion of outcrossing. The work of Santos-Gally et al. (2013) must have also been inspirational to Simón-Porcar as she developed her hypothesis because their study showed a clear connection between the narrow corolla and the evolution of style polymorphism in Narcissus. With these previous studies in mind, Simón-Porcar has boldly proposed adding an alternative origin to the Lloyd and Webb (1992) model and directed future researchers towards taxa and methods to use to test this hypothesis.

\section{References}

Arroyo, J. and S.C.H. Barrett. 2000. Discovery of distyly in Narcissus (Amaryllidaceae). American Journal of Botany 87: 748-751. CrossRef

Arroyo, J., Barrett, S.C.H., Hidalgo, R. and W.W Cole. 2002. Evolutionary maintenance of stigma-height dimorphism in Narcissus papyraceus (Amaryllidaceae). American Journal of Botany 89: 12421249. CrossRef

Barrett, S.C.H., Lloyd, D.G. and J. Arroyo. 1996. Stylar polymorphisms and the evolution of heterostyly in Narcissus (Amaryllidaceae). Pages 339-376 in Lloyd, D.G., and S.C.H. Barrett, editors. Floral biology: Studies on floral evolution in animalpollinated plants. Chapman and Hall, New York. CrossRef

Barrett, S.C.H., Jesson, L.K. and A.M. Baker. 2000. The evolution and function of stylar polymorphisms in flowering plants. Annals of Botany 85 (Supplement A): 253-265. CrossRef

Casper, B.B., Sayigh L.S. and S.S. Lee. 1988. Demonstration of cryptic incompatibility in distylous Amsinckia douglasiana. Evolution 42: 248-253. CrossRef

Cesaro, C., Barrett, S.C.H., Maurice, S., Vaissiere, B.E. and J.D. Thompson. 2004. An experimental evaluation of self-interference in Narcissus assoanus: functional and evolutionary implications. Journal of Evolutionary Biology 17: 1367-1376. CrossRef

Charlesworth, D. and B. Charlesworth. 1979. A model for the evolution of distyly. The American Naturalist 114: 467-498. CrossRef

Cohen, J.I., A. Litt, and J.I. Davis. 2009. Comparative floral development in Lithospermum (Boraginaceae) and implications for the evolution and development of heterostyly. American Journal of Botany 99: 797805. $\underline{\text { CrossRef }}$ 
Darwin, C. 1877. The different forms of flowers on plants of the same species. John Murray, London. CrossRef

Faivre, A.E. 2000. Ontogenetic differences in heterostylous plants and implications for development from a herkogamous ancestor. Evolution, 54: 847-858. CrossRef

Graham, S.W. and S.C.H. Barrett. 2004. Phylogenetic reconstruction of the evolution of stylar polymorphisms in Narcissus (Amaryllidaceae). American Journal of Botany 91: 1007-1021. CrossRef

Lloyd, D.G. and C.J. Webb. 1992. The selection of heterostyly. Pages 179-208 in Barrett, S.C.H., editor. Evolution and function of heterostyly: Monographs on theoretical and applied genetics, Springer-Verlag, Berlin. CrossRef

Nowak, M.D., Russo, G., Schlapbach, R., Huu, C.N., Lenhard, M. and E. Conti. 2015. The draft genome of Primula veris yields insights into the molecular basis of heterostyly. Genome Biology 16: 1-16. CrossRef

Santos-Gally, R., González-Voyer, A. and J. Arroyo. 2013. Deconstructing heterostyly: the evolutionary role of incompatibility system, pollinators and floral architecture. Evolution 67: 2072-2082. CrossRef

Schoen, D.J., Johnston, M.O., L'Heureux, A. and J.V. Marsolais. 1997. Evolutionary history of mating system in Amsinckia (Boraginaceae). Evolution 51: 1090-1099. CrossRef

Simón-Porcar, V.I. 2018. Late-acting selfincompatibility and a narrow floral tube as selective forces for stylar dimorphism in Narcissus (Amaryllidaceae). Ideas in Ecology and Evolution 11: 64-73. $\underline{\text { CrossRef }}$ 